Citation: A. Gabarda-Mallorquí, R.M. Fraguell (2020) La pandemia COVID-19y los Objetivos de Desarrollo Sostenible. Estrategias para la reconversión de los destinos turísticos de masas españoles. Bollettino della Società Geografica Italiana serie 14, 3(1): 15-25. doi: 10.36253/bsgi.v3i1.940

Copyright:@2020A. Gabarda-Mallorquí, R.M. Fraguell. This is an open access, peer-reviewed article published by Firenze University Press (http://www. fupress.com/bsgi) and distributed under the terms of the Creative Commons Attribution License, which permits unrestricted use, distribution, and reproduction in any medium, provided the original author and source are credited.

Data Availability Statement: All relevant data are within the paper and its Supporting Information files.

Competing Interests: The Author(s) declare(s) no conflict of interest.

\section{La pandemia COVID-19 y los Objetivos de Desarrollo Sostenible. Estrategias para la reconversión de los destinos turísticos de masas españoles}

\section{COVID-19 pandemic and the Sustainable Development Goals. Strategies to Spanish mass tourist destinations restructure}

\author{
Ariadna Gabarda-Mallorquí, Rosa Maria Fraguell \\ Departamento de Geografía e Instituto de Medio Ambiente, Universidad de Girona, Spain. \\ E-mail: ariadna.gabarda@udg.edu, rosa.fraguell@udg.edu
}

\begin{abstract}
The recent COVID-19 pandemic has put the mass tourism sector in Spain in check. The measures to contain the spread of the virus have led to the loss of millions of euros and thousands of jobs in the sector. There are three factors regarding mass tourism management that make the sector even more fragile, jeopardizing its recovery once the pandemic is under control: currently, tourist destinations cannot yet guarantee physical distance, their work structure is not inclusive, and there are not enough multi-sector global alliances. These three circumstances do not allow the sector to be more resilient and able to face future outbreaks. The United Nations Sustainable Development Goals are, today more than ever, essential for the adaptation of the sector to new post-COVID-19 phases. Thus, with a strategy based on objectives 3,8 and 17 , the sector will move towards healthier, more inclusive and more cooperative tourist destinations, being able to face new outbreaks and even future health crises.
\end{abstract}

Keywords: COVID-19, mass tourism, Sustainable Development Goals, Spain, tourist destinations.

Resumen. La reciente pandemia del COVID-19 ha puesto en jaque al sector turístico de masas en España. Las medidas de contención de la expansión del virus han supuesto la pérdida de millones de euros y miles de puestos de trabajo del sector. Tres son los factores relacionados con el turismo de masas que hacen aun más frágil al sector y ponen en peligro su recuperación: actualmente los destinos turísticos aún no pueden garantizar la distancia física, su estructura laboral no es inclusiva y existen pocas alianzas multi-sectoriales globales que le permitirían ser más resiliente y hacer frente a futuros rebrotes. Los Objetivos de Desarrollo Sostenible de las Naciones Unidas son, hoy más que nunca, esenciales para la adaptación del sector a nuevas fases post-COVID-19. Así, con una estrategia basada en los objetivos 3, 8 y 17, el sector caminará hacia unos destinos turísticos más saludables, más inclusivos y más cooperativos siendo capaces así de hacer frente a nuevos rebrotes e incluso futuras crisis sanitarias. 
Palabras clave: COVID-19, turismo de masas, Objetivos de Desarrollo Sostenible, España, destinos turísticos.

\section{Introducción}

El turismo es el sector económico de mayor crecimiento a nivel mundial, incluso durante los últimos años ha sido superior al previsto por diferentes organizaciones mundiales. Según datos apuntados por la Organización Mundial del Turismo (OMT), en 2018 las llegadas de turistas internacionales alcanzaron los 1.401 millones y el total de ingresos también por turismo internacional fueron de 1.451 miles de millones de dólares (USD), con un crecimiento respecto al año anterior del 5,4\% y del 4,4\%, respectivamente (OMT 2019). Hasta la actualidad, la tendencia del sector turístico es de seguir un crecimiento más acelerado que el resto de los sectores económicos. En el 2018, y por séptimo año consecutivo, las exportaciones turísticas crecieron más rápido que las exportaciones de mercancías. $\mathrm{Su}$ importancia respecto al conjunto de la economía mundial se manifiesta en el hecho de que representa el $7 \%$ de las exportaciones mundiales (29\% de las exportaciones de servicios), ocupando la tercera posición después de los sectores de los productos químicos y los combustibles, y de que aporta el 10,4\% al PIB global y ocupa uno de cada diez puestos de trabajo en el mundo (con un global de 319 millones), según el World Travel \& Tourism Council (WTTC 2019).

La tendencia de los últimos años, con un ritmo de crecimiento del sector turístico acelerado, ha quedado interrumpido como consecuencia del impacto inesperado de la COVID-19. La pandemia causada por un nuevo Coronavirus se ha convertido en una auténtica sacudida a nivel mundial, interrumpiendo la actividad económica, cancelando todos los desplazamientos internacionales y cerrando la actividad de empresas y negocios. Del overtourism se ha pasado al non-tourism (Gössling, Scott, Hall 2020). Debido a la rápida expansión del virus, millones de personas han estado confinadas hasta que las autoridades han podido tener un mínimo control de la pandemia. Referente al turismo, uno de los sector más afectados por esta crisis sanitaria, y con fecha 27 de marzo de 2020, la OMT hace público un comunicado donde prevé que en este mismo año tanto las llegadas como los ingresos derivados del turismo internacional global tendrán una caída entre un $20 \%$ y un 30\% respecto al 2019. En mayor o menor medida, esto puede representar una desaceleración de entre cinco y siete años de crecimiento. Probablemente es la crisis más fuerte de la historia del turismo moderno, una crisis sin precedentes y que hace difícil evaluar la magnitud de su impacto por su acelerada evolución y, en consecuencia, difícilmente se pueden prever los futuros acontecimientos. Incluso las dos crisis que la han precedido no se acercan a la gravedad de los efectos de la presente pandemia. En este sentido, la producida por la epidemia del SARS que tuvo lugar durante el año 2003 supuso una reducción de las llegadas y los ingresos también por turismo internacional de tan sólo el $0,4 \%$ y el 1,4\%, respectivamente. Durante la crisis económica mundial de 2009 , la pérdida por las llegadas y los ingresos de turismo internacional fueron del orden del $4 \%$ y el 5,4\%, respectivamente.

En cualquier caso, el sector turístico ha pasado de ser el sector más dinámico a nivel económico al más dañado por dos motivos clave. En primer lugar, el turismo es sinónimo de movilidad y la mayor parte de los desplazamientos turísticos al extranjero se realizan en avión, medio de transporte principal del turismo internacional (en el 2018 el 58\% utiliza este medio de transporte) (OMT 2019). Como consecuencia de la crisis, muchas compañías aéreas han dejado de operar, afectando, especialmente, a las compañías de bajo coste. En segundo lugar, el miedo a viajar se ha generalizado, produciéndose una pérdida de confianza en la seguridad de los destinos por la mala imagen que han transmitido como espacios de riesgo para la salud, tanto de turistas como de residentes.

El presente artículo tiene como objetivos analizar, por un lado, la afectación que la crisis de la COVID-19 está teniendo ya sobre el sector turístico español y, por otro, explorar posibles vías de reconversión del sector, basadas en los 17 Objetivos de Desarrollo Sostenible de las Naciones Unidas (17 ODS), para que el turismo se convierta en un nuevo modelo post-COVID-19 en pro de la sostenibilidad y capaz de hacer frente a futuras crisis sanitarias minimizando los impactos que derivan de largas interrupciones de la actividad económica y de confinamientos restrictivos.

\section{El turismo masivo en España: orígenes de un turismo depredador e insostenible}

El turismo en España se puede dividir en cinco grandes fases: la etapa proto-turista (mediados y finales del siglo XIX), la pre-fordista (primer cuarto del siglo $\mathrm{XX}$ ), la fordista - inicio del turismo masivo de sol y playa - (décadas de los 50, 60 y 70), la de estancamiento (décadas de los 80 y 90) y la post-fordista (finales del siglo XX e inicios del XXI) (Cànoves, Prat, Blanco 2016). 
La fase pre-fordista en España coincide con la segunda periferia definida por Gormsen $(1981 ; 1997)$ y que se desarrolla en localidades como San Sebastián (País Vasco) en el Cantábrico o Sant Feliu de Guíxols (Costa Brava, Cataluña) en el Mediterráneo. Esta periferia coincide con entornos marítimos templados e inviernos suaves. La demanda, formada por la aristocracia y la burguesía industrial, se siente atraída por la búsqueda de espacios con paisajes bien preservados y tranquilos, donde descansar, y saludables, donde practicar la talasoterapia, basada en sacar provecho de las propiedades beneficiosas del agua del mar y del clima marino.

Durante la fase fordista, coincidente con la tercera periferia definida por Gormsen $(1981 ; 1997)$ y que en España alcanza su máximo desarrollo a lo largo del litoral mediterráneo, el turismo vivió una auténtica explosión con un crecimiento urbanístico descontrolado y un elevado consumo de suelo, sobre todo en espacios ubicados en la primera línea de costa (Donaire 2005). Tanto fue el crecimiento que ya en 1970 España representaba el 15\% del mercado turístico mundial. Los turistas de sol y playa, atraídos por la climatoterapia y el bronceado, aparecen pues durante esta fase. Los recursos naturales y climáticos presentaban grandes potencialidades y fueron ampliamente explotados y comercializados como productos turísticos de primer orden. En plena dictadura franquista, el turismo masivo de sol y playa era visto entonces como un medio para asegurar una rentabilidad elevada y así aumentar los ingresos (Almeida 2014). Tanto fue así, que incluso el desarrollo turístico en España fue concebido como la alternativa al Plan Marshall, paquete de financiación rechazado por el gobierno franquista. Este crecimiento descontrolado y sin planificación se materializó en la artificialización de buena parte del litoral mediterráneo español, el aumento descontrolado de suelo urbanizado y la especulación y la rentabilidad inmobiliaria (Navarro-Jurado, Thiel-Ellul, Romero-Padilla 2015). Es durante esta etapa que las actividades turísticas de sol y playa alcanzan su pico máximo (Gabarda-Mallorquí, Ribas Palom 2016). Las provincias litorales de Girona, Alicante, Málaga, las Islas Baleares y dos provincias de las Islas Canarias representan entre el 80 y el 85\% de todas las pernoctaciones internacionales en España durante los años 60 y 70s (Vasallo 1999). Las regiones litorales se convirtieron pues en los principales destinos turísticos del Mediterráneo ofreciendo 3 de los recursos turísticos naturales con más potencial del momento: Sun, Sand y Sea (las tradicionales 3 "S" del turismo de costa masivo), a las que también se añade más tarde la cuarta "S" de Sex, tal y como afirma Crick (1989).

El caso de Benidorm, en la provincia de Alicante, es un buen ejemplo de la gran transformación de los destinos turísticos litorales. Este municipio se convirtió en el referente turístico por excelencia del turismo masivo del período fordista en España. Su Plan General de Ordenación Urbana (PGOU), aprobado en 1956 (el primero en el estado español), fue diseñado inicialmente siguiendo el modelo de ciudad jardín de los destinos turísticos pre-fordistas de la Costa Azul francesa, pero la revisión hecha en 1963 dio paso a la ciudad vertical, conservando la trama urbana aprobada años antes, pero permitiendo la libertad total en las alturas y en las densidades del espacio edificado. El Plan tenía una clara funcionalidad turística, tuvo mucho éxito entre la demanda y durante años la ciudad de Benidorm, gracias a su planificación urbanística, fue considerada como el milagro español (Ivars, Rodríguez, Vera 2013). De hecho en España, durante los años cincuenta, se definieron las bases del sistema turístico territorial, que fue aprobado definitivamente en los años sesenta con la Ley de Centros y Zonas de Interés Turístico Nacional (CyZITN). Aunque en un principio pretendía ser un proyecto ambicioso intentando relacionar la política económica con el desarrollo turístico y con la ordenación del territorio, en realidad fue un fracaso y quedó reducido a una simple figura de planificación que tenía por objetivo promocionar la construcción de nuevos asentamientos turísticos urbanos masivos, tanto en las zonas de litoral como de alta montaña. En este sentido, favoreció determinadas áreas regionales, donde el turismo aún no había tenido un desarrollo intensivo, como es el caso de Isla Canela (Ayamonte) o Nueva Andalucía - Puerto Banús (Marbella) en las zonas litorales, o de Formigal (Sallent de Gállego) o Astún (Jaca) en las zonas de alta montaña (Galiana, Barrado, 2006).

A mediados - finales de los años 80 se detectan los primeros síntomas de cansancio y desequilibrio del modelo turístico fordista, sobre todo de tipo territorial y ambiental, y que se manifiesta con la estabilización del número de llegadas de turistas internacionales. Pero esta crisis no implica una renuncia al turismo masivo de sol y playa, sino una diversificación del producto y una renovación de los destinos y establecimientos turísticos. En este nuevo contexto, con muchos elementos de continuidad respecto al período precedente, el medio ambiente y la sostenibilidad toman protagonismo. Para algunos autores las nuevas políticas de reestructuración y su puesta en práctica son un reflejo de la adaptación de las zonas turísticas en el nuevo marco del post-fordismo, también llamado modelo Neo-fordist sun-andsand (Aguiló, Alegre, Sard 2005). Después de un largo período de estancamiento durante las décadas de los 80 y 90, el turismo en España en términos globales vuelve a recuperarse, tanto en el número de visitantes como 


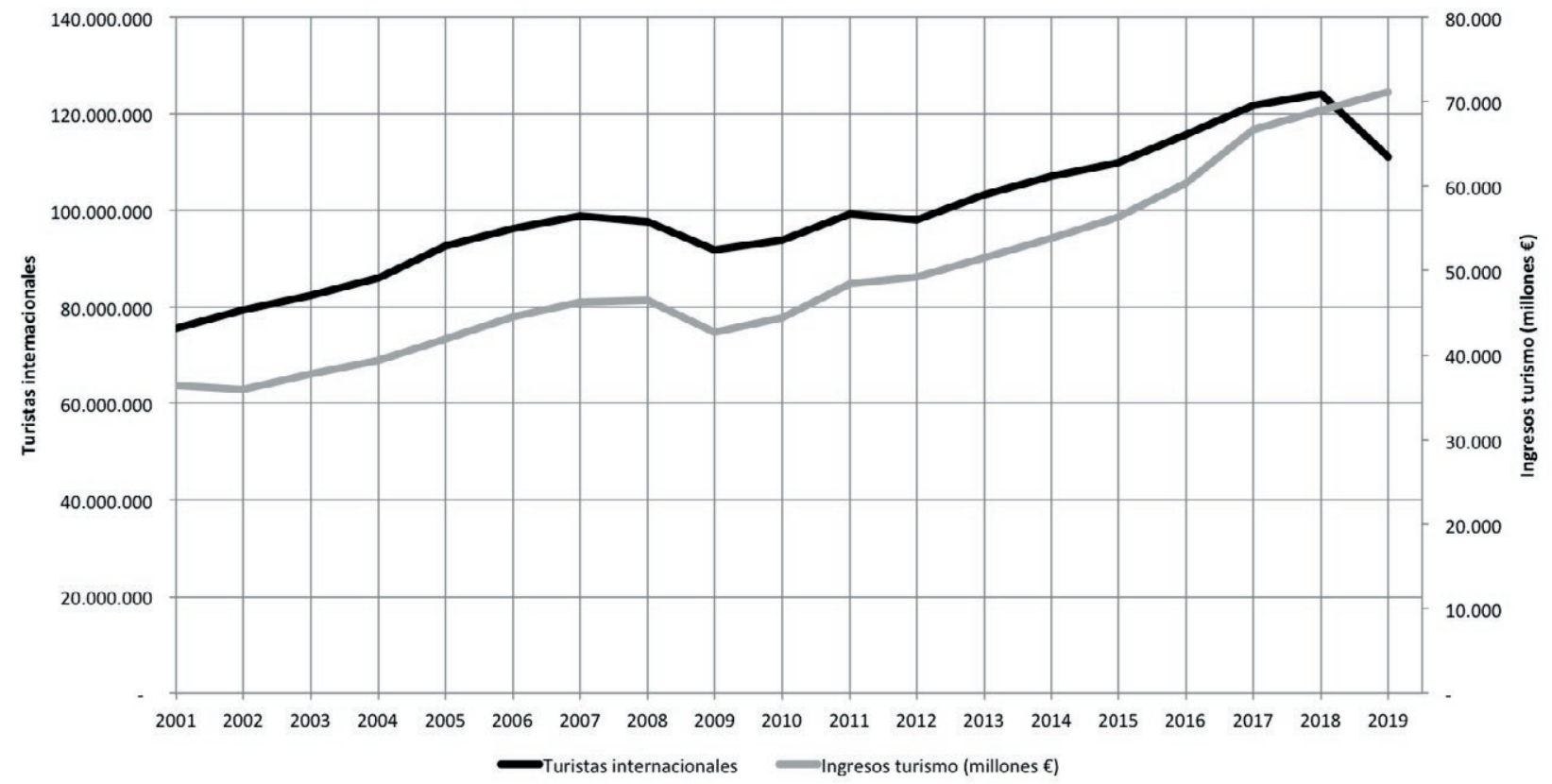

Figura 1. Evolución del número de visitantes y los ingresos derivados del turismo internacional en España, 2001-2019. Fuente: elaboración propia a partir de datos extraídos de Frontur (tourspain.es, último acceso 5 de mayo de 2020).

de ingresos por turismo internacional (Fig. 1). La etapa post-fordista se caracteriza por la gestión pública del sector a partir de organismos reguladores y normativos que permiten reordenar lo poco que queda después del gran boom urbano-turístico litoral del período fordista anterior.

La planificación territorial turística desde los años 90 parte del discurso de la contención urbanística y de la protección de los espacios naturales. Sin embargo, en determinadas regiones, como las Islas Baleares, y en períodos de crisis, este discurso se ha alternado con políticas neoliberales de reconversión que han dado lugar a nuevos crecimientos urbano-turísticos (Blázquez, Artigues, Yrigoy 2015). A raíz de la publicación de la Carta Mundial del Turismo Sostenible, presentada en la I Conferencia Mundial de Turismo Sostenible, celebrada en Lanzarote entre el 24 y 29 de abril de 1995, surgen programas donde el concepto de la sostenibilidad es el eje principal y que serán trascendentales en la gestión de los destinos y actividades turísticas. En España estas nuevas políticas turísticas culminan con la aprobación por el Consejo de Ministros el 8 de noviembre de 2007 del Plan de Turismo Español Horizonte 2020, un plan que responde al compromiso internacional de España con la revalorización del sistema turístico (Cañizares 2013). Gracias al establecimiento de este nuevo discurso en pro de la sostenibilidad, se crean numerosas agencias públicas que diseñan y aprueban marcos legislativos de ordenación, planificación y/o protección del territorio (Almeida 2014). Los destinos turísticos costeros, con el objetivo de diversificar su oferta, buscan nuevos productos para llegar a otros turistas, no sólo los que buscan sol y playa, basados en los recursos culturales y naturales locales (espacios naturales protegidos, espacios culturales...). Esta renovación, sin embargo, no implica una renuncia al turismo de masas, sino que lo mantiene y ofrece además otros productos orientados a nuevas tipologías turísticas.

Sin embargo, la irrupción en el mercado de las compañías aéreas de bajo coste, que perpetúan el turismo masivo, y las nuevas formas de consumo incentivan entre los destinos de sol y playa en España la aparición de nuevos turistas que buscan en la costa no sólo 4 sino las 5 "S" (Sun, Sand, Sea, Sex y Sangría). Esta bebida de base alcohólica muy popular y consumida en época estival y relacionada con los destinos de sol y playa, representa la nueva "S" que convierte ciertos destinos turísticos litorales en espacios de un ocio nocturno exacerbado con un excesivo consumo de alcohol. Son conocidos los casos de Magaluf (Mallorca), San Antonio (Ibiza), Salou (Tarragona) o la Barceloneta (Barcelona), lugares donde durante el verano se convierten en auténticas junglas repletas de turistas irresponsables e irrespetuosos que consumen alcohol de forma casi incontrolada, produ- 
ciéndose a menudo problemas de salud y desgastando la marca España como un destino de calidad y segura. Este overtourism conduce a situaciones de terribles consecuencias, con un agravamiento de la calidad de vida de residentes y un deterioro de los destinos (Fletcher et al. 2019).

\section{Afectación de la crisis COVID-19 al sector turístico masivo en España}

El 12 de febrero de 2020, se hacía pública la decisión de suspender la edición del Mobile World Congress de este año debido a la rápida expansión de un nuevo Coronavirus (SARS-CoV-2). La cancelación de este evento que se celebra en Barcelona desde el año 2006, que genera cerca de 500 millones de $€$ y unos 14.100 puestos de trabajo temporal, ya hacía entrever la grave crisis sanitaria que tarde o temprano debía estallar en Europa. En efecto, y una vez en España los contagios fueron no importados sino producidos dentro de sus fronteras, las posteriores medidas llevadas a cabo para evitar la propagación del Coronavirus han provocado una paralización de la economía con lo que se espera conlleve a una fuerte recesión. En España, se prevé que el impacto de la COVID-19 sea aún más grave que el de la gripe española de 1918. Durante el primer trimestre del 2020, la economía española se ha desplomado un 5,2\%. Hasta entonces, la mayor caída del PIB trimestral fue del 2,6\% en el año 2009 con la crisis económica y financiera, que tuvo una repercusión importante también en el sector turístico. El consumo en los hogares también ha presentado un fuerte retroceso del 7,5\%. Sin embargo, el gobierno prevé que la crisis de la COVID-19 sea aún mayor hasta llegar a una caída del 9,2\% del PIB y una tasa de paro del $19 \%$. En España, que ocupa uno de los primeros lugares en la lista de los países con más contagios y fallecidos por coronavirus, el gobierno reconoce que el sector turístico será uno de los más afectados por la crisis, siendo el primero en cerrar puertas y el último en abrirlas. El hecho de que la crisis de la COVID-19 haya aparecido en España durante el mes de febrero y marzo, el segmento turístico que se verá más ampliamente afectado es el de sol y playa. La temporada de verano para el 2020 no se puede asegurar y se prevén unos impactos sociales y económicos como nunca antes se han vivido. Las cuatro comunidades autónomas más afectadas en términos laborales han sido Baleares, Canarias, Andalucía y la Comunidad Valenciana, cuatro regiones donde el turismo es un sector económico estructural y donde el paro registrado ha aumentado significativamente en términos relativos. En unas declaraciones hechas en una entrevista al diario
El País, en fecha del 12 de abril de 2020, la Ministra de Industria, Comercio y Turismo, Reyes Maroto, reconocía que "el sector turístico será de los últimos en superar la crisis".

Contrariamente, el impacto de las dos últimas crisis (la primera de tipo sanitario y la segunda económico) fue mucho menor. De acuerdo con los datos publicados en Frontur y Egatur por los años 2003 y 2009 (tourspain. es, último acceso el 5 de mayo de 2020), durante la crisis sanitaria del SARS en 2003, las llegadas de turismo internacional se mantuvieron prácticamente igual que el año anterior (con un pequeño repunte del 0,3\%). En cambio, los ingresos derivados cayeron un $2 \%$. A pesar de que la caída general no fue muy grave, se puede observar que esta crisis no afectó tanto en las llegadas, sino que sólo se notó una desaceleración y estancamiento, pero, en cambio, sí afectó a los ingresos en mayor medida si se compara con la media a nivel mundial $(-1,4 \%)$, lo que demuestra que España no genera tanta confianza sanitaria en aquellos turistas más exigentes y con mayor poder adquisitivo. Contrariamente, la crisis económica iniciada en 2008-2009, frenó de manera considerable las llegadas de turismo internacional en un $-8,7 \%$. Los ingresos también experimentaron una caída del $-6,7 \%$. El hecho de que la reducción en los ingresos fuese menor que la relativa a las llegadas muestra que la crisis económica afectó con más intensidad al turismo masivo de poco poder adquisitivo. Además en ambos casos, a pesar de las caídas puntuales, el turismo demostró su fuerza y capacidad de resiliencia, de adaptación y de generar empleo inmediato. De hecho, el sector turístico, respecto a otros sectores económicos, es el que siempre se ha recuperado más rápidamente después de las crisis económicas ocurridas desde la segunda mitad del siglo XX (Navarro-Jurado et al. 2015). Sin embargo, la crisis sanitaria actual parece no tener precedentes y todo apunta a que no es como las anteriores crisis, sino que esta vez son necesarias acciones concisas, firmes y coordinadas con otros sectores (Gössling et al. 2020). Los datos publicados en diferentes medios hablan por sí solos. En España, las pérdidas para el sector serán millonarias, tanto en ingresos como en puestos de trabajo generados. Las pérdidas se aproximarán a los 100.000 millones de euros y se destruirán 1,7 millones de puestos de trabajo (de un total de 2,6 para el conjunto de la industria turística).

En términos generales, hay tres razones básicas que explican los efectos devastadores que está teniendo la COVID-19 sobre el sector turístico en España. Como se apuntaba anteriormente, un buen número de destinos turísticos españoles reciben anualmente millones de visitantes, que se concentran en pueblos y ciudades 
masificadas. El turismo de masas ha movido la economía desde la década de los 50 y sigue siendo el motor del sector. Esta modalidad turística tan intensiva conlleva a una acumulación de visitantes en espacios muy reducidos como son las playas, los centros urbanos y/o los medios de transporte público. Ahora mismo, el sector no es capaz de asegurar la distancia física mínima de seguridad sin renunciar a buena parte de los ingresos. En este sentido, en muchos destinos se ha priorizado la cantidad más que la calidad y se ha querido sacar el máximo beneficio (o máximo rendimiento) por unidad de superficie. Este modelo intensivo de turismo sólo puede ser rentable con la llegada masiva de visitantes. Sin embargo, la obligación de mantener la distancia física para evitar más contagios entra en contradicción con la naturaleza de la industria turística de masas. El turismo masivo no es pues Saludable.

Referente al mercado laboral relacionado con el sector turístico español, cabe destacar que buena parte de su mano de obra no está suficientemente cualificada ni bien pagada. En algunos casos, incluso se contrata personal con salarios muy por debajo de lo estipulado en los convenios y las regulaciones laborales. Las plantillas laborales están formadas mayoritariamente por personal no cualificado (ayudantes no titulados, auxiliares, peones...), categoría que forman el $89,9 \%$ del total de empleados. Estos puestos de trabajo más vulnerables tienen un mayor riesgo de ser efectuados en entornos con malas condiciones de trabajo, con desigualdad de oportunidades de promoción e incluso de acoso laboral (Oficina Internacional del Trabajo, 2017). El resto de la plantilla está formada por un $5,2 \%$ de jefes de administración y talleres, un 3,5\% de ingenieros, licenciados y personal directivo y un $1,5 \%$ de personal técnico, peritos y ayudantes titulados (EXCELTUR, 2018). El mercado laboral del sector turístico viene dimensionado por la demanda que, en el caso de España, es totalmente variable e irregular (Cañada, 2017). De este modo, las contrataciones en el sector son también variables y se ajustan únicamente a la demanda y a la estacionalidad, sin tener en cuenta otros criterios que permitirían mejorar las condiciones laborales y estabilizar las plantillas. Cabe destacar también que la temporalidad de los contratos laborales dificulta el reciclaje formativo y la capacitación del personal. Para la próxima temporada de verano del 2020, la falta de demanda provocará un número muy bajo de contrataciones. Buena parte del personal que debía ser contratado quedará automáticamente sin empleo y con muy poca capacidad de ser reubicada en un mercado laboral ya de por sí bastante restringido. El turismo masivo no es en este caso Inclusivo.

Los destinos turísticos tienen una fuerte vincula- ción entre ellos a través de numerosas redes y alianzas, tanto a nivel regional como nacional e internacional. El sector público que gestiona el turismo trabaja en muchas ocasiones en red, compartiendo retos y transformando el sector desde una perspectiva global. Destacan redes de destinos para el turismo sostenible como la Red de Destinos Turísticos Inteligentes (destinosinteligentes. es/) a nivel regional, o bien NECSTouR, la Red de Regiones Europeas para el Turismo Sostenible y Competitivo (necstour.eu) a nivel europeo y de la que forman parte regiones como Andalucía, las Islas Baleares, Cataluña o las Islas Canarias, entre otros. Todos estos organismos se convierten en un espacio de diálogo idóneo para que los destinos que los integran puedan compartir buenas prácticas, siendo así un canal efectivo de difusión y de transferencia de conocimiento. A pesar de las múltiples redes, las alianzas entre el sector público y el privado son a menudo inexistentes. Los destinos de masas consolidados no funcionan a través de un engranaje mixto entre la administración y la industria turística, sino que las relaciones entre ambos agentes está llena de obstáculos. Las diferentes estrategias definidas por los dos sectores topan con una realidad muy compleja, haciendo que sea realmente complicado establecer unas sinergias positivas para el logro de un objetivo común. La crisis de la COVID-19 está generando grandes pérdidas en el sector turístico y las empresas de este sector se juegan en gran medida su continuidad si no colaboran conjuntamente con la administración para generar el clima de confianza y seguridad que necesita la demanda turística. En este sentido, el turismo masivo no es Cooperativo.

\section{Los 17 Objetivos de Desarrollo Sostenible en España: la estrategia para unos destinos turísticos saludables, inclusivos y cooperativos}

Los 17 Objetivos de Desarrollo Sostenible (ODS) fueron aprobados por las Naciones Unidas en septiembre de 2015. De hecho son la herencia y la reformulación de los Objetivos de Desarrollo del Milenio (Fukuda-Parr 2016). Los 17 ODS se convierten pues en el marco de referencia para el desarrollo sostenible de la comunidad internacional para el período 2015-2030 (Le Blanc 2015). Durante el 2017, año declarado por las Naciones Unidas como el Año Internacional del Turismo Sostenible para el Desarrollo, se identifican los destinos turísticos como los espacios idóneos para la aplicación de los 17 ODS. De este modo, se subraya el hecho de que el turismo es un actor clave y fundamental que contribuye activamente al desarrollo sostenible. El informe de 2019 del Sustainable Development Goals (SDG), estudio anual que elabora 


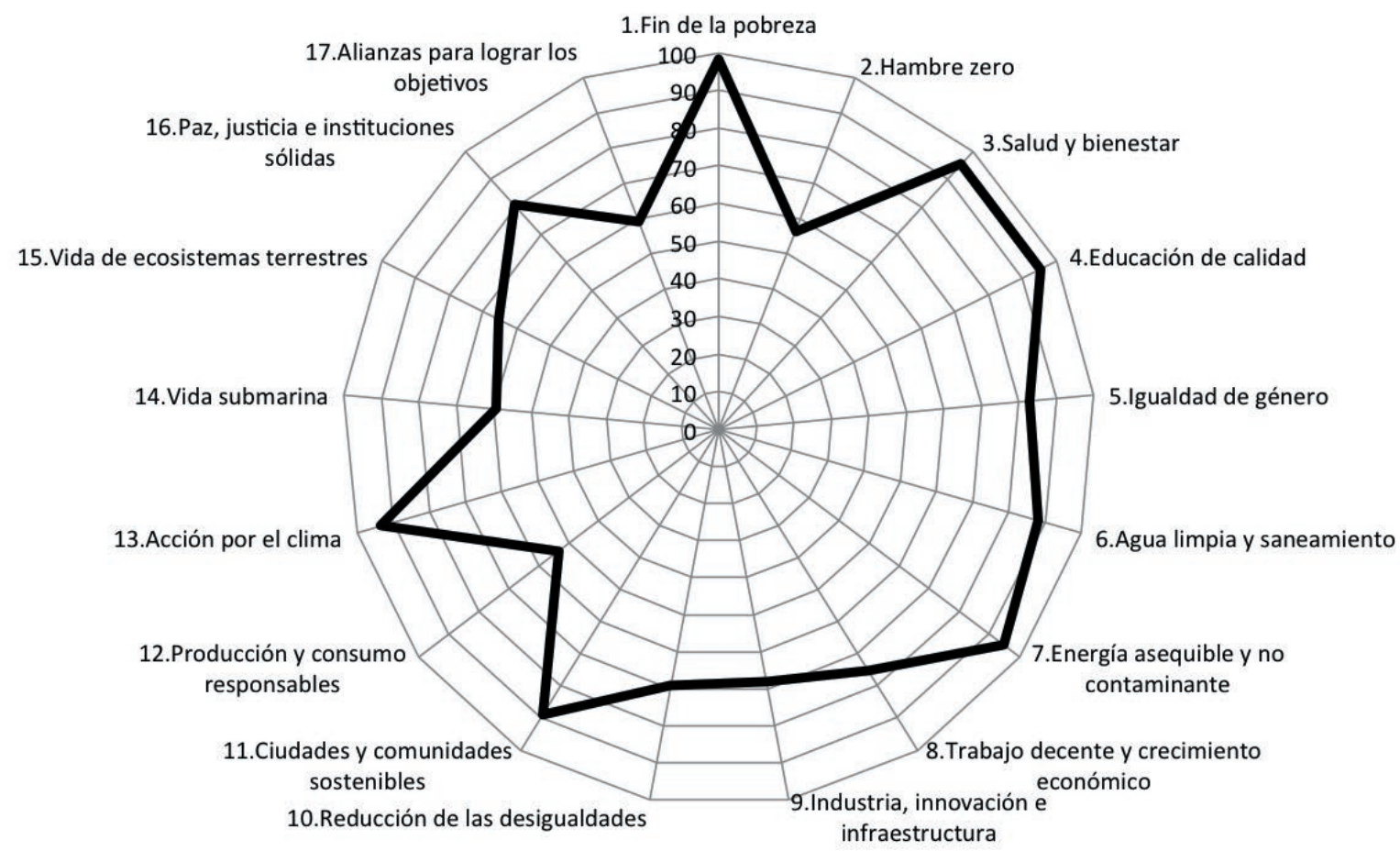

Figura 2. Puntuación de España para cada uno de los 17 ODS, 2018. Fuente: elaboración propia a partir de datos extraídos de sdgindex.org.

la Sustainable Development Solutions Network (SDSN), evalúa el grado de cumplimiento de los 17 ODS en 162 países a partir de 83 indicadores (Sachs, Schmidt-Traub, Kroll, Lafortune, Fuller 2019). España, un país con un grado de desarrollo elevado en el sector turístico (ocupa la segunda posición en dicho ranking del 2018 tanto en llegadas de turistas internacionales como en ingresos) y altamente golpeado por los efectos de la COVID-19, obtiene una puntuación global elevada: se sitúa en la posición 21 de entre los 162 países evaluados, con una puntuación de 77,8 sobre 100 , de acuerdo con el resultado para cada uno de los 17 ODS (Fig. 2).

Una vez controlados los picos de la pandemia de la COVID-19, es importante destacar que los ODS enmarcan perfectamente las estrategias que el nuevo modelo turístico post-COVID-19 debe materializarse con el fin de lograr la reconversión de manera eficiente, fortaleciendo unas destinos más saludables, más inclusivos y más cooperativos. De este modo, los objetivos 3, 8 y 17 (Figura 3) se convierten en la punta de lanza de todas las acciones e instrumentos encarados a la reconversión del sector: buen estado de salud para garantizar las condiciones sanitarias necesarias para luchar contra la pandemia del Coronavirus y/o futuras pandemias; mano de obra digna y más tecnificada para evitar una elevada pérdida de puestos de trabajo; y alianzas multisectoriales para consolidar y fortalecer la colaboración entre el sector público y la industria privada. En este sentido, actualmente España muestra un buen estado en términos de salud y de bienestar, pues en relación al Objetivo 3 obtiene una puntuación de 95,4 puntos sobre 100. En cambio, referente al Objetivo 8 sobre un trabajo decente y crecimiento económico sostenido tiene una puntuación de 75,2 y, en consecuencia, muestra una mayor debilidad. Del mismo modo, en cuanto a establecer complicidades para hacer frente a problemáticas globales y poderlas superar conjuntamente (ODS 17), España obtiene una puntuación de tan solo 59,1.

Objetivo 3. Garantizar una vida saludable y promover el bienestar para todos y en todas las edades

De acuerdo con este objetivo, uno de los principales retos planteados es el de fortalecer la capacidad para la alerta precoz de emergencias sanitarias, la reducción del riesgo sanitario y la gestión de los riesgos asociados tanto nacionales como globales. En este sentido, para la reconversión del sector a un turismo post-COVID-19 se hacen necesarias las acciones encaminadas a (1) Desarrollar un sistema eficiente de seguridad para prevenir, contro- 

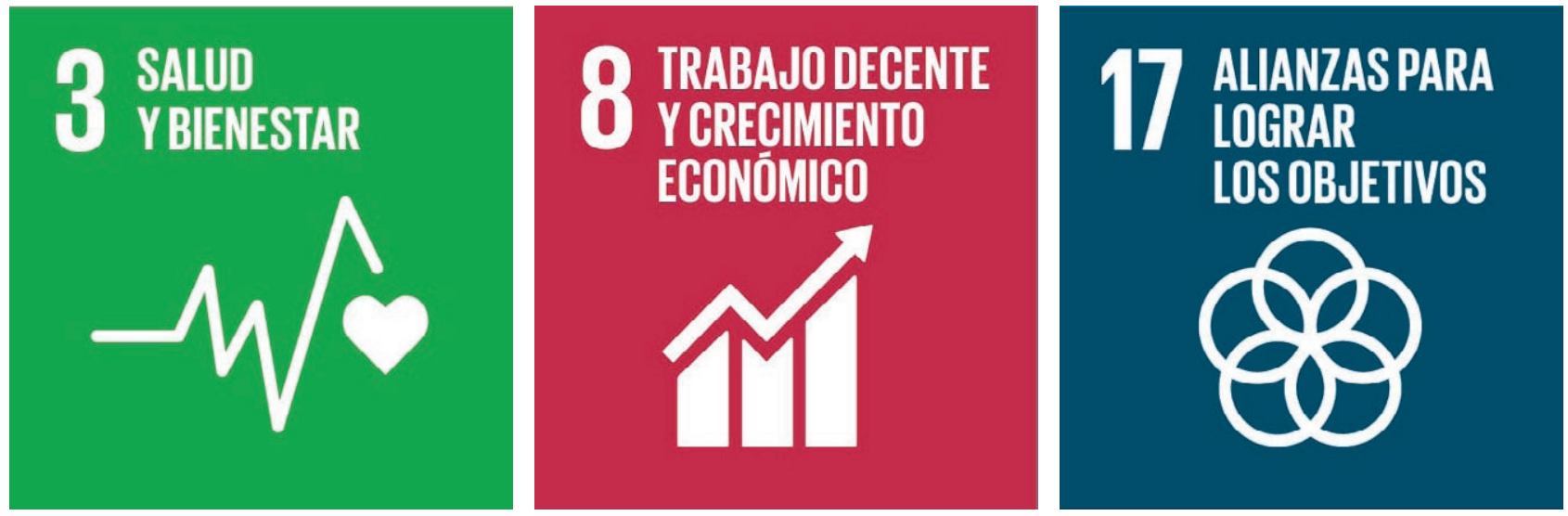

Figura 3. Los Objetivos de Desarrollo Sostenible 3, 8 y 17. Fuente: imágenes extraídas de un.org/sustainabledevelopment.

lar, informar públicamente y dar respuesta ante posibles peligros que atenten contra la salud y integridad física de residentes y visitantes, (2) Asegurar el desarrollo, la promoción y la priorización de productos y actividades turísticas saludables, (3) Reforzar la capacidad de contribuir a la mejora de la asistencia sanitaria ofrecida en los núcleos turísticos, y (4) Mejorar la capacidad para identificar, prevenir, planificar y dar respuesta a los riesgos ambientales $y$ emergencias reales y potenciales que puedan poner en peligro la salud y integridad física de residentes y visitantes (Azcárate et al. 2019). La reconversión del sector, a partir de la propia reorganización infraestructural (reduciendo el número de plazas, cerrando los espacios comunes si no se puede garantizar la distancia física, reforzando las buenas prácticas higiénicas o garantizando los productos de desinfección personal, entre otras medidas), todo esto sin poner en peligro la disponibilidad y la calidad de recursos, como el agua y los alimentos, y erradicando todo desarrollo turístico basado en el consumo de alcohol y de drogas y en la promiscuidad sexual.

Objetivo 8. Promover un crecimiento económico inclusivo y sostenible a partir de puestos de trabajo dignos para todos

Los grandes retos del sector para dignificar y tecnificar la mano de obra pasan por conseguir un mayor nivel de productividad económica a partir de la diversificación, la actualización tecnológica y la innovación. El turismo debería ser una poderosa herramienta de desarrollo local para la reducción de la desigualdad, creando empleo digno y productivo, así como ser parte activa para el crecimiento económico sostenible. También se hace necesario promover políticas y planes estratégicos para la creación de puestos de trabajo dignos y la formalización de micro, pequeñas y medianas empresas garan- tizando así el acceso equitativo a fuentes de financiación. Para todo ello, el mercado laboral debe ser inclusivo y equitativo, tanto en términos de valorización como de remuneración, para mujeres y hombres, jóvenes y personas con capacidad multifuncional y debe respetar y proteger los derechos laborales de todos los trabajadores. De acuerdo con Azcárate et al. (2019), las estrategias para la consecución de un mercado laboral inclusivo deben pasar indudablemente por el (1) Desarrollo de medidas orientadas a la generación de empleo local cualificado y seguro favoreciendo el emprendimiento en actividades y servicios turísticos sostenibles así como también para la (2) Promoción de la modernización, la diversificación y la innovación tecnológica en el sector turístico, en aras de aumentar tanto la productividad (sobre todo en aquellas labores que requieren un uso intensivo de mano de obra), como el turismo sostenible, la promoción de la cultura y el uso de productos locales, entre otros. La dignificación de los puestos de trabajo y un mercado laboral más tecnificado evitaría situaciones de pérdida masiva de empleo en el sector turístico debido a una crisis como la actual. Aumentando las rentas familiares de los trabajadores del sector, permitiría a los hogares hacer frente con más solvencia a situaciones de desempleo. Además, la regularización del conjunto de las plantillas evitaría casos de no acceso a las ayudas y prestaciones del sistema público. Si el sector tiende hacia una tecnificación de su mano de obra, ésta será parte de la solución para minimizar los impactos derivados de las medidas de contención de la pandemia (confinamiento, interrupción de la actividad económica...) ya que este segmento de la plantilla colaboraría activamente en los nuevos planes de reconversión. Así, técnicos sanitarios, de prevención de riesgos, informáticos, ingenieros, arquitectos, biólogos o geógrafos deben formar parte de las plantillas laborales 
de las empresas turísticas, representando un porcentaje mucho más elevado que el actual.

Objetivo 17. Revitalizar la alianza mundial para el desarrollo sostenible

La OMT defiende que, dado el carácter multisectorial, el turismo tiene la capacidad de reforzar las asociaciones público-privadas y de involucrar a múltiples stakeholders, desde la escala local a la internacional, con el fin de contribuir al desarrollo sostenible (Azcárate et al. 2019). De hecho, el objetivo 17 hace referencia también a los medios y las vías para el logro del resto de los 16 objetivos (Fukuda-Parr 2016). Los retos incluidos en este objetivo son diversos y de distinta idiosincrasia. En cuanto a la coherencia institucional y política, hay que decir que es necesario mejorar la estabilidad económica global con coherencia y coordinación política, respetando el liderazgo de cada uno de los países a la hora de establecer e implementar políticas de desarrollo sostenible. Referente a las alianzas multisectoriales, hay que caminar hacia una mejor alianza global complementada por redes formadas por múltiples agentes que permita compartir conocimiento, experiencia, tecnología y recursos financieros. Sin duda, hay que alentar y promover alianzas entre los agentes públicos, privados y civiles. En un escenario post-COVID-19, el sector turístico debe reconvertirse a partir de (1) Formar parte de redes, proyectos o alianzas globales y regionales para el turismo sostenible en cualquiera de sus facetas, (2) Promover y facilitar el intercambio de buenas prácticas y conocimientos tanto del propio destino como los relativos a experiencias externas, que permitan inspirar la replicación de casos de éxito en el turismo sostenible local, y (3) Desarrollar iniciativas de cooperación con instituciones académicas $u$ otras entidades, ya sea a través de acuerdos y convenios públicos o privados, para favorecer la innovación en el desarrollo sostenible del turismo en todos los ámbitos, incluyendo la gestión y la valoración del conocimiento como recurso turístico (Azcárate et al. 2019). Estas propuestas incentivan el diseño de nuevas estrategias que son necesarias para luchar contra el aislamiento y la no colaboración entre todos los gestores de los destinos turísticos, tanto públicos como privados. Una mejora de las redes público-privadas con el establecimiento de un nuevo modelo de gobernanza turística es esencial para la búsqueda de soluciones compartidas por el bien común siempre a partir de la cooperación entre todos los agentes implicados. Las alianzas turísticas multi-sectoriales y bottom-up deben ser la base de cualquier estrategia de gestión de los destinos turísticos.

\section{Conclusiones}

La pandemia del nuevo Coronavirus y las medidas de contención de la propagación derivadas, han puesto entre las cuerdas el sistema económico mundial, interrumpiendo toda actividad económica y confinando a buena parte de la población. Los efectos están siendo devastadores para un sistema que parecía disfrutar de plena inmunidad, con un crecimiento constante a la vez que insostenible. El turismo, actividad económica estructural de muchas regiones, sobre todo en la cuenca del Mediterráneo, será uno de los sectores más damnificados. En España, el sector turístico masivo, que ya se sustentaba en fundamentos frágiles y poco resilientes, está viviendo la peor crisis de la historia, haciendo que sea necesaria una reformulación de todos los elementos que lo componen. La era post-COVID-19 constituye una nueva fase que obliga a todos los agentes implicados a repensar cuál ha sido el camino recorrido y reestructurar los pilares para hacer frente a esta y nuevas pandemias futuras. La COVID-19 debe convertirse en un auténtico revulsivo para capacitar al sector y hacer frente a una nueva etapa hasta hoy desconocida.

Los ODS deben ser pues la base de todas las estrategias de reconversión de los destinos turísticos masivos haciéndolos más saludables (ODS3), donde se aseguren las condiciones higiénicas y sanitarias necesarias para evitar la propagación del virus; más inclusivos (ODS8), con una dignificación, diversificación y tecnificación de la mano de obra a fin de hacerla más robusta y más resiliente a nuevos brotes de la COVID-19 o de futuras pandemias globales; y más cooperativos (ODS17), para crear y consolidar nuevas alianzas multi-sectoriales bottom-up, donde el sector privado coopere y colabore con el público, y viceversa. El sector debe considerar todas las acciones e instrumentos que son clave para la reconversión de los destinos turísticos. Acciones creativas e ingeniosas para minimizar los efectos de la caída del sector y asegurar una actividad mínima para la temporada de verano 2020 .

Ahora más que nunca el turismo debe y puede reinventarse, dejando de lado el culto al "número" y priorizando la calidad por delante de la cantidad, convirtiéndose en un sector sostenible, respetuoso con el entorno y la población residente, promoviendo la buena convivencia y la diversidad cultural, protegiendo y recuperando la biodiversidad y fomentando empleos dignos y equitativos. 


\section{Referencias}

Aguiló, E., Alegre, J., Sard, M. (2005). The persistence of the sun and sand tourism model. Tourism Management, 26(2), 219-231. https://doi.org/10.1016/j. tourman.2003.11.004

Almeida, F. (2014). A comparative study of the evolution of tourism policy in Spain and Portugal. Tourism Management Perspectives, 11, 34-50. https://doi.org/10.1016/j. tmp.2014.03.001

Azcárate, T., Benayas, J., Nerilli, G., Justel, A. (2019). Guía para un turismo sostenible. Retos y criterios para la evaluación del sector turístico ante la agenda 2030. Madrid, REDS.

Blázquez, M., Artigues, A. A., Yrigoy, I. (2015). Crisis y planificación territorial turística neoliberal en las Islas Baleares. Investigaciones Turísticas, 9, 24-49. https:// doi.org/10.14198/inturi2015.9.02

Cañada, E. (2017). Un turismo sostenido por la precariedad laboral. Papeles de Relaciones Ecosociales y Cambio Global, 140, 65-73.

Cañizares, M. C. (2013). Sostenibilidad y turismo: de la documentación internacional a la planificación en España «horizonte 2020». Boletín de La Asociación de Geógrafos Españoles, 61, 67-92. https://doi.org/10.21138/bage.1536

Cànoves, G., Prat, J. M., Blanco, A. (2016). Tourism in Spain, beyond the sun and the beach. Recent evolution and changes in coastal destinations towards cultural tourism. Boletín de La Asociación de Geógrafos Españoles, 71, 431-454. https://doi.org/10.21138/bage.2289

Crick, M. (1989). Representations of International Tourism in the Social Sciences. Annual Review of Anthropology, 18, 307-344.

Donaire, J. A. (2005). La lògica espacial del turisme a la Costa Brava. In COAC (Ed.), Debat Costa Brava. Un futur sostenible. Girona, 218-225.

EXCELTUR. (2018). Informe Ejecutivo Empleo En El Sector Turístico. https://www.exceltur.org/wp-content/ uploads/2018/04/ESTUDIO-EMPLEO-SECTOR-TURISTICO-EXCELTUR.pdf

Fletcher, R., Murray, I., Blanco-Romero, A., BlázquezSalom, M. (2019). Tourism and degrowth: an emerging agenda for research and praxis. Journal of Sustainable Tourism, 27(12), 1745-1763. https://doi.org/10.1080/096 69582.2019.1679822

Fukuda-Parr, S. (2016). From the Millennium Development Goals to the Sustainable Development Goals: shifts in purpose, concept, and politics of global goal setting for development. Gender and Development, 24(1), 43-52. https://doi.org/10.1080/13552074.2016.1145895

Gabarda-Mallorquí, A., Ribas Palom, A. (2016). Understanding reductions in water consumption in tourist areas: a case study of the Costa Brava, Spain. International Journal of Water Resources Development, 32(6). https:// doi.org/10.1080/07900627.2016.1142861

Galiana, L., Barrado, D. (2006). Los Centros de Interés Turístico Nacional y el despegue del turismo de masas en España. Investigaciones Geográficas, 39(39), 73-93. https://doi.org/10.14198/ingeo2006.39.04

Gormsen, E. (1981). The spatio-temporal development of international tourism: attempt at a centre-periphery model. Études \& Memoires, 55, 150-169.

Gormsen, E. (1997). The impact of tourism on coastal areas. GeoJournal, 42(1), 39-54. https://doi. org/10.1023/A:1006840622450

Gössling, S., Scott, D., \& Hall, M. (2020). Pandemics, tourism and global change: a rapid assessment of COVID-19. Journal of Sustainable Tourism, 1-20. https://doi.org/10.1080/09669582.2020.1758708

Ivars, J. A., Rodríguez, I., Vera, J. F. (2013). The evolution of mass tourism destinations: New approaches beyond deterministic models in Benidorm (Spain). Tourism Management, 34, 184-195. https://doi.org/10.1016/j. tourman.2012.04.009

Le Blanc, D. (2015). Towards Integration at Last? The Sustainable Development Goals as a Network of Targets. Sustainable Development, 23(3), 176-187. https://doi. org/10.1002/sd.1582

Navarro-Jurado, E., Thiel-Ellul, D., \& Romero-Padilla, Y. (2015). Periferias del placer: Cuando turismo se convierte en desarrollismo inmobiliario-turístico. Boletín de La Asociación de Geógrafos Españoles, 67, 275-302. https://doi.org/10.21138/bage.1826

Oficina Internacional del Trabajo (OIT) (2017). Pautas de la OIT sobre trabajo decente y turismo socialmente responsable. Ginebra. https://doi.org/10.1016/j.schres.2009.04.005

Organización Mundial del Turismo (OMT) (2019). Panorama del turismo internacional, edición 2019. https:// www.e-unwto.org/doi/pdf/10.18111/9789284421237

Sachs, J., Schmidt-Traub, G., Kroll, C., Lafortune, G., Fuller, G. (2019). Sustainable Development Report 2019. Transformations to Achieve the Sustainable Development Goals. New York. 
Vasallo, I. (1999). Crisis y consolidación, 1972-1982.

In Bayón, F., Marcos, H., Vogeler, C., González, M. A. (Eds.), 50 años del turismo español: un análisis histórico y estructural. Madrid, Centro de Estudios Ramón Areces, 105-124.

World Travel \& Tourism Council (WTTC) (2019). You've reached your destination. Best practices enabling the growth of travel \& tourism. https://wttc.org/en-gb/ Research/Insights 